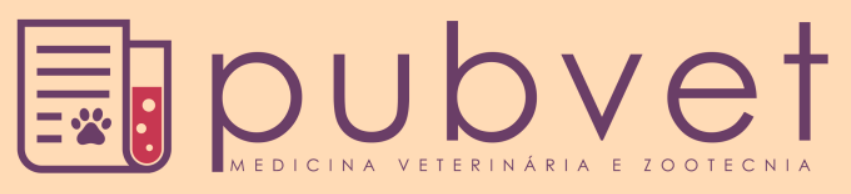

https://doi.org/10.22256/pubvet.v12n4a62.1-10

\title{
Suplementação estratégica para animais em pasto
}

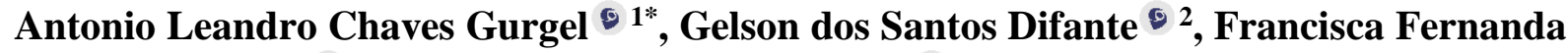 \\ da Silva Roberto ${ }^{\ominus 3}$, Joederson Luiz Santos Dantas ${ }^{\bullet}$
}

\begin{abstract}
${ }^{l}$ Universidade Federal do Rio Grande do Norte. Mestrado em Produção Animal, Macaíba, RN, Brasil. Antonioleandro09@gmail.com. ${ }^{2}$ Universidade Federal do Rio Grande do Norte, Zootecnia, Macaíba, RN. Brasil. gdifante@ @otmail.com. ${ }^{3}$ Universidade Federal do Rio Grande do Norte. Mestrado em Produção Animal, Macaíba, RN, Brasil.nnandinha_roberto@yahoo.com.br. ${ }^{4}$ Universidade Federal do Rio Grande do Norte. Mestrado em Produção Animal, Macaíba,RN,Brasil.joedersondantas@outlook.com.

*Autor para correspondência
\end{abstract}

RESUMO. A produção de ruminantes no Brasil é baseada quase que exclusivamente em pasto, pois, estes são capazes de prover substratos energéticos de baixo custo, principalmente a partir dos carboidratos fibrosos. Porém, plantas forrageiras na maioria das vezes quando usadas como fonte exclusiva na dieta de ruminantes não atendem as exigências do animal devido a reconhecida flutuação das exigências nutricionais, o que compromete o rendimento, sinalizando para a necessidade de suplementar os animais, com a finalidade de fornecer nutrientes que estão limitando o desempenho. A suplementação deve ser usada como meio de maximizar a utilização da forragem disponível, sendo que o consumo de forragem dos animais pode permanecer inalterado, aumentar ou diminuir, o que torna o conhecimento dessa prática um desafio para se obter os resultados almejados, tendo em mente que o suplemento não deve fornecer nutrientes além das exigências dos animais, com isso tem-se reduzido a frequência de fornecimento do suplemento para animais em pasto. Tendo como finalidade, um melhor aproveitamento da mão de obra na distribuição do suplemento e redução dos custos sem afetar o desempenho dos animais.

Palavras chave: alimentação a pasto, desempenho animal, forragem, produção animal

\section{Strategic supplementation for grazing animals}

ABSTRACT. The production of ruminants in Brazil is based exclusively on grazing, since they are able to provide low cost energy substrates, mainly from fibrous carbohydrates. However, forage plants in most cases when used as an exclusive source in the ruminant diet do not meet the requirements of the animal due to the recognized fluctuation of nutritional requirements, which compromises the yield, signaling to the need to supplement the animals, for the purpose of providing nutrients that are limiting performance. Supplementation should be used to maximize the utilization of the available forage, and the forage consumption of the animals can remain unchanged, increase or decrease, which makes the knowledge of this practice a challenge to obtain the desired results, keeping in mind that the supplement should not provide nutrients beyond the requirements of the animals, thereby reducing the frequency of delivery of the supplement for grazing animals. The aim is to make better use of labor in distributing the supplement and reducing costs without affecting the performance of the animals.

Keywords: animal performance, animal production, forage, grass feed 


\section{Suplementación estratégica para animales en pasto}

RESUMEN. La producción de rumiantes en Brasil se basa casi exclusivamente en pasto, pues, estas son capaces de proveer sustratos energéticos de bajo costo, principalmente a partir de los carbohidratos fibrosos. Sin embargo, las plantas forrajeras la mayoría de las veces cuando se utilizan como fuente exclusiva en la dieta de rumiantes no atienden las exigencias del animal debido a la reconocida fluctuación de las exigencias nutricionales, lo que compromete el rendimiento, señalando la necesidad de suplementar los animales, con la finalidad de proporcionar los nutrientes que están limitando el rendimiento. La suplementación debe utilizarse como medio para maximizar la utilización del forraje disponible, siendo que el consumo de forraje de los animales puede permanecer inalterado, aumentar o disminuir, lo que hace que el conocimiento de esta práctica sea un reto para obtener los resultados deseados, teniendo en cuenta que el suplemento no debe suministrar nutrientes además de las exigencias de los animales, con lo que se ha reducido la frecuencia de suministro del suplemento para animales en pasto. Con el fin, un mejor aprovechamiento de la mano de obra en la distribución del suplemento y reducción de los costos sin afectar el desempeño de los animales.

Palabras clave: alimentación a pasto, rendimiento animal, forraje, producción de animales

\section{Introdução}

O Brasil possui 170 milhões de hectares de pastagens, destas 100 milhões são de pastagens cultivadas (ANUALPEC, 2017), apesar dessas grandes áreas os índices zootécnicos do rebanho brasileiro ainda são insatisfatórios, havendo necessidade de estudos acerca do adequado manejo das pastagens, com objetivo de alcançar maior produção de forragem e produção animal. Nas pesquisas sempre se busca forrageiras com elevada produção de biomassa por unidade de área e elevado valor nutritivo. O baixo desempenho é justificado pelo fato das condições ideais de cultivo e da produção de biomassa das gramíneas forrageiras tropicais no Brasil não serem constantes ao longo do ano, principalmente causa dos períodos de baixas precipitações ou demais fatores abióticos. Aliado a isso, as plantas forrageiras na maioria das vezes quando usadas como fonte exclusiva na dieta de ruminantes não atendem as exigências do animal devido a reconhecida flutuação das exigências nutricionais, o que compromete o rendimento (Hodgson, 1990, NRC, 2000).

Surge assim, a necessidade de se estabelecer estratégias de fornecimento de nutrientes que viabilizem, da melhor forma possível, os padrões de crescimento estabelecidos pelo sistema de produção (Prado et al., 2010, Fernandes et al., 2017). A solução para esses problemas pode ser obtida combinando-se adequadamente alternativas de manejo de pastagens e suplementação alimentar, visto que os sistemas modernos de criação, com adoção de práticas de manejo e alimentação adequadas, possibilitam melhor desempenho dos animais e, por consequência, melhor retorno econômico (Cardoso et al., 2006). Nas principais regiões produtoras de carne bovina do país, há grande variação na produção e na qualidade das forragens durante o ano e essas variações são apontadas como as principais responsáveis pelos baixos índices produtivos obtidos no Brasil (Prado et al., 2010). A vedação (reserva de pasto) ou a pressão de pastejo moderada durante a estação das águas são boas opções para amenizar os efeitos negativos da reduzida, ou até mesmo nula, taxa de crescimento das forrageiras durante os meses de seca (Amorim et al., 2017). Entretanto, esse manejo provoca acúmulo de caules e tecidos senescentes, que terão maiores teores de lignina e fibra e menor proporção de proteína bruta (PB). A suplementação, no entanto, pode corrigir em parte essas deficiências, melhorando o aproveitamento dessas forragens pelos bovinos na época seca do ano (Simioni et al., 2009).

A suplementação em pasto é destinada para suprir as deficiencias da pastagem e equilibrar o ambiente ruminal (Geron et al., 2012), sempre utilizando as quantidades adequadas para cada categoria. A condição básica para uso da suplementação é que haja elevada disponibilidade de massa forrageira na pastagem, mesmo sendo de baixa qualidade.

O objetivo dessa revisão é realizar um levantamento bibliográfico sobre o efeito da suplementação no desempenho dos animais em Pasto. 


\section{Aspectos gerais da suplementação}

O termo suplementação para animais em pastejo é muitas vezes usado inadequadamente, uma vez que ele é conceituado como um complemento da dieta, o qual supre os nutrientes deficientes da forragem disponível, visando equilibrar a dieta do animal (Geron et al., 2012), quando na verdade a suplementação utilizada na grande maioria das propriedades brasileiras, gira em torno de $0,2 \%$ a $0,5 \%$ do peso vivo do animal (Morais et al., 2009, Simioni et al., 2009), não atendendo as necessidades do animal (NRC, 2000), portanto, a suplementação para animais em pastejo é o complemento da dieta, o qual supre os nutrientes deficientes da forragem disponível para manter um adequedo funcionamento ruminal, elevando o suprimento de energia metabolizável que, aliado a quantidades satisfatórias de proteína degradável no rúmen aumenta a síntese de proteína microbiana.

A proteína microbiana é normalmente a principal fonte de proteína metabolizável (PM) para ruminantes, podendo representar mais de 65\% da PM em animais mantidos exclusivamente em pasto (Berchielli et al., 2011), portanto todo e qualquer programa nutricional só terá sucesso se a produção de proteína microbiana for otimizado (Valadares Filho et al., 2016). Uma das formas de se aumentar a produção microbiana é a aumentar a quantidade de substrato para os microrganismos, sendo que com o uso da suplementação ocorre aumento na quantidade de substrato para fermentação e com isso aumenta a quantidade de proteína microbiana produzida (Berchielli et al., 2011). Aliado a isso, maiores produções de proteína microbiana aumentam a degradabilidade, diminui o tempo de retenção da forragem no rúmen, incrementando o desempenho animal.

Todavia, para obter os resultados esperados pelo uso da suplementação é preciso ter conhecimento dos efeitos desta, e as respostas do animal aos diferentes tipos de suplementos, que podem alterar a ingestão de matéria seca, o desempenho animal e a taxa de digestão (Bargo et al., 2003).

Ao se suplementar os animais em pasto, o consumo de forragem dos animais pode permanecer inalterado, aumentar ou diminuir, sendo que as respostas dependem da quantidade e qualidade da forragem disponível, bem como da característica química do suplemento utilizado e do potencial genético do animal (Reis et al., 2009). Segundo Dixon \& Stockdale (1999), interações entre pasto e suplementação podem acontecer, e o entendimento desta é importante para uma exploração mais eficiente dessa prática de manejo.

Para Silva et al. (2010), as respostas na relação entre a forragem disponível e a suplementação alimentar podem ser aditivas, substitutivas, aditivas substitutivas, aditivas com estímulo e substitutiva com redução (Figura 1).

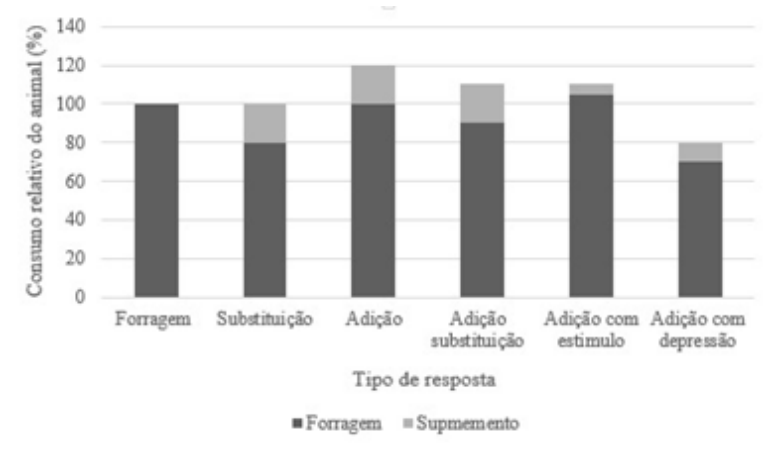

Figura 1. Esquema simplificado das respostas do animal a suplementação.

Quando o efeito é substitutivo não ocorre incremento no consumo, sendo que a quantidade de suplemento ingerida substitui parte da forragem (diminui o consumo de forragem). Pode ser benéfico, quando há suplementação, os animais podem substituir parte da ingestão de lâminas foliares pelo suplemento, como consequência verifica-se diferenças na estrutura do pasto (Farinatti et al., 2006). Portanto, o uso de suplemento além de melhorar o desempenho individual, poderá aumentar a produtividade, devido os animais substituírem parte da ingestão de lâminas foliares pelo suplemento, havendo um incremento na taxa de lotação. Já o efeito aditivo, ocorre quando o consumo de suplemento não interfere no consumo de forragem, seria avaliado com o aumento de ganho de peso, proporcionado pelo aumento do consumo de matéria seca via suplemento, ou seja, o consumo de forragem é constante em diferentes níveis de suplementação e ocorre adição no consumo total no mesmo nível que em o suplemento é fornecido (Reis et al., 2009).

Existem basicamente duas formas de utilização de suplementos: suprir nutrientes limitantes (normalmente nitrogênio não proteico) tendo como objetivo atingir níveis de mantença, tipo de suplementação mais utilizado em períodos secos, onde a forragem apresenta baixos níveis de proteína bruta; suprir nutrientes energéticos e/ou proteicos objetivando maior ganho de peso vivo. Nesse contexto, os suplementos concentrados são 
aqueles que apresentam em sua composição química menos de $18 \%$ de fibra bruta, podendo ainda, ser classificados em: suplemento concentrado proteicos, quando apresentam $20 \%$ ou mais de proteína bruta na matéria seca. Já aqueles que apresentam menos de $20 \%$ de proteína bruta são classificados com suplementos energéticos (NRC, 2000, Valadares Filho et al., $\underline{2016)}$.

Sendo que a resposta do animal a qualquer forma de suplementação dependerá das características da forragem, tanto em termos qualitativos como quantitativos, portanto, a resposta da suplementação irá variar ao longo do ano devido a estacionalidade na produção forrageira (Moreira et al., 2003, Moreira et al., 2004b, Moreira et al., 2005).

\section{Suplementação na época seca}

A maioria dos sistemas de produção de ruminantes em regiões tropicais é baseada em sistemas de produção que utilizam gramíneas forrageiras com fonte primária de alimento, pois, estas são capazes de fornecer substratos energéticos de baixo custo, a partir de carboidratos fibrosos (Prado, 2010, Berchielli et al., 2011). Contudo, as gramíneas tropicais raramente podem ser consideradas dieta equilibrada para animais em pastejo, pois, estas irão exibir invariavelmente uma ou mais limitações nutricionais que causarão restrições sobre o consumo de pasto, a digestão da forragem ou a metabolizabilização dos substratos absorvidos (Berchielli et al., 2011).

Além disso, as características do pasto variam durante o ano, devido ao natural desenvolvimento fenológico e o efeito direto de fatores abióticos que limitam o desenvolvimento da planta (Moreira et al., 2004a). Em geral, no início do período das águas, o percentual de lâminas foliares vivas é alto, comparativamente ao teor de colmo e de tecidos mortos (Emerenciano Neto et al., 2017). Já no período seco ocorrem modificações na estrutura do pasto, que impossibilitam o animal de colher lâmina foliar viva de forma análoga ao que ocorre no início do período chuvoso, mesmo com a capacidade de seleção pelo animal (Reis et al., 2009, Gurgel et al., 2017).

De encontro a essas constatações, na época seca as folhas das gramíneas forrageiras, apresentam altos valores das frações fibrosas, e valores de proteína bruta inferiores a 7\% na matéria seca (Gurgel et al., 2017), limitando a atividade de microrganismos. Consequentemente, verifica-se diminuição da digestibilidade da fração fibrosa da forragem e da produção de ácidos graxos voláteis, importantes fontes de energia para os ruminantes (Minson, 2012), diminuição da produção de proteína microbiana, o que sinaliza para a necessidade de suplementação para animais nessa época do ano, principalmente proteica. Todavia, as bactérias ruminais necessitam da disponibilidade de ATP, pois, quando é fornecida proteína na dieta, com forragem com baixa degradabilidade, a disponibilidade de energia pode limitar o crescimento microbiano, dessa forma a suplementação para animais em pastejo deve apresentar natureza proteico/energético (Moore et al., 1999).

Tonello et al. (2011) realizaram uma metaanálise sobre o efeito da suplementação no desempenho de bovinos de corte em pastagens nas diferentes épocas do ano, observaram que na época das águas a concentração de proteína bruta das forragens é em média de $10,6 \%$ enquanto na época seca ocorre uma redução de $25,7 \%$ do teor de proteína bruta das forragens, atingindo valores médio de $7,88 \%$. Esta alteração na qualidade da forragem, no entanto, deve ser compensada com o acréscimo de proteína na suplementação, com isso o ganho médio diário dos animais na época das águas é em média de $0,14 \mathrm{~kg} / \mathrm{dia}$ e na época das secas de 0,26 kg/dia. Esses mesmos autores relataram um consumo de NDT via suplemento pelos animais é de $0,63 \%$ do PV/dia, valor superior ao consumido na época das águas $(0,42 \%$ do $\mathrm{PV} /$ dia), isso provavelmente devido ao menor valor nutritivo das forragens na época seca, o que leva os animais a consumir mais nutrientes via suplemento para suprir as deficiências das forragens. Esse maior consumo de NDT pode incrementar o consumo voluntário de forragem de baixa qualidade devido ao aumento nos níveis de substratos nitrogenados disponíveis para as bactérias, com elevação na taxa de digestão e síntese de proteína microbiana. Nesse contexto, Gurgel et al. (2017) quando suplementaram ovinos em pastos de capim-massai nos meses da estação seca no nordeste do Brasil, observaram maior ganho médio diário quando comparados aos resultados obtidos por Emerenciano Neto et al. (2014), no período das águas, sem o uso de suplementação. $\mathrm{O}$ suplemento fez com que a produtividade animal ( $\mathrm{kg}$ de $\mathrm{PV} /$ ha.dia) no período seco alcançasse valores próximos ao do período das águas $(0,99$ e 1,14 kg de PV/ha.dia, na seca e nas águas, respectivamente), apesar da 
menor taxa de lotação, devido a maior disponibilidade de forragem no período chuvoso.

Euclides et al. (1998) avaliaram diferentes regimes alimentares de novilhos mantidos em pastagem tropical e observaram que os animais suplementados com concentrado nos períodos críticos por dois anos seguidos, alcançando valores superiores a $1 \mathrm{~kg} / \mathrm{animal} / \mathrm{dia}$ no primeiro período, enquanto que os animais nãosuplementados apresentaram ganhos de apenas $0,32 \mathrm{~kg} / \mathrm{animal} / \mathrm{dia}$ no primeiro ano, perdendo peso no segundo ano. Os autores observaram ainda que a suplementação com concentrado durante o período seco foi capaz de reduzir a idade de abate dos animais de 5 a 13 meses. O que diminui o tempo de permanência dos animais no sistema, possibilitando maior rotatividade.

Fernandes et al. (2017) avaliaram a estrtrutura do pasto de capim-massai pastejado por ovinos suplementados com diferentes fontes de proteína mais mistura múltipla em comparação à suplementação apenas com mistura múltipla no periodo seco do ano. Não foi observado diferenças na estrutura do pasto em função do tipo de suplementação, porém foi observado ofertas de forragem acima da media para o periodo. Demosntrando o efeito da suplementação na estrutura do pasto, isso ocorre provavelmente devido a interação suplemento/ forragem, com predominnncia para o efeito substitutivo, ou seja, o consumo total é constante, porém o consumo de forragem diminui na mesma proporção que aumenta o consumo de suplemento (Reis et al., 2009), o que possibilita maoires ganhos por aréa.

A suplementação possibilita maiores indices de desempenhos para animais em pasto melhora as condições estruturais da pastagem e também é eficiente na reprodução de matrizes bovinas. $\mathrm{O}$ aumento nos níveis de suplemento proporciona melhoria no estado corporal final aos animais, conferindo maior probabilidade de retorno a atividade ovulatória (Restle et al., 2000). Tem-se reduzido a frequência de suplementação para animais em Pasto. Tendo Como finalidade, diminuir gastos com mão de obra na distribuição do suplemento e redução dos custos e não se tem observado queda no desempenho (Goes et al., 2005).

O fato da digestão e o desempenho não serem fortemente afetados pela frequência de suplementação, pode ser reflexo da habilidade de animais ruminantes em manterem o suprimento de nitrogênio no ambiente ruminal por meio da reciclagem, em níveis que não inibem o crescimento microbiano (Moraes et al., 2010). Ao avaliarem o efeito da frequência de suplementação sobre os parâmetros ruminais de bovinos de corte em pastejo no período da seca, Moraes et al. (2010) observaram que a concentração de amônia $\left(\mathrm{NH}_{3}\right)$ ruminal, não limitou o crescimento microbiano em nenhuma das estratégias de suplementação. Mesmo nos dias em que os animais não receberam suplementos, os níveis estiveram acima dos 10,0 mg/dL de líquido ruminal sugeridos por Leng (1990) como ótimo para apropriada fermentação em condições tropicais (Figura 2).

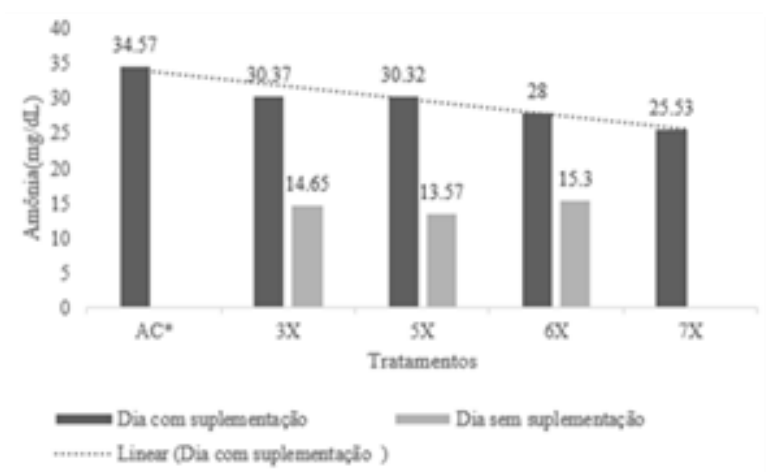

Figura 2. Estimativa da concentração de NH3 do líquido ruminal obtida no dia do fornecimento do suplemento e no dia sem suplementação (adaptado de Moraes et al. (2010)) *Autocontrole (Mistura múltipla).

A maior concentração de $\mathrm{NH}_{3}$ ruminal nos animais que consumiram suplemento autocontrole (Figura 2) pode ser atribuída à alta taxa de hidrólise da ureia. Também foi observado decréscimo na concentração de $\mathrm{NH}_{3}$, a medida em que se aumentou a frequência de suplementação, o que reforça a ideia da habilidade de animais ruminantes em manterem o suprimento de $\mathrm{N}$ no ambiente ruminal por meio da reciclagem. Para Bohnert et al. (2002), os ruminantes são eficientes em manter níveis adequados de nitrogênio no ambiente ruminal entre os períodos de suplementação, de modo que essa manutenção do nitrogênio pode ser atribuída a possíveis alterações na permeabilidade do trato gastrintestinal à ureia e/ou na regulação da excreção da ureia.

Morais et al. (2009) avaliando a influência da frequência de suplementação no consumo, na digestibilidade e na fermentação ruminal em novilhos de corte mantidos em pastagem de capim-marandu, constataram que a redução na frequência da suplementação de sete para cinco ou três vezes por semana não afeta a ingestão de matéria seca, tanto de forragem como total, nem a 
digestibilidade da matéria seca. Da mesma forma, o pH ruminal, as concentrações da amônia ruminal e dos ácidos graxos de cadeia curta, importantes para a manutenção adequada da fermentação ruminal, são mantidos quando a frequência de suplementação diminui.

Diante disso, Simioni et al. (2009) quando forneceram suplemento concentrado nos níveis de $0,3 \%$ e $0,6 \%$ do peso vivo de novilhos de corte em pasto na estação seca, diariamente e em dias alternados, observaram que a suplementação com $0,6 \%$ do peso corporal promoveu ganho médio diário de $343 \mathrm{~g}$ e ganho total de $28,9 \mathrm{~kg}$, valores superiores aos encontrados para $0,3 \%$ do peso corporal, de $238 \mathrm{~g}$ e $20,2 \mathrm{~kg}$, respectivamente, devido o maior aporte de nutrientes. Todavia, com relação a frequência, a suplementação diária não foi vantajosa em relação à suplementação em dias alternados para ganho médio diário, ganho de peso total e para a relação $\mathrm{kg} / \mathrm{kg}$ de alimento consumido, independentemente do nível de suplementação estudado.

Canesin et al. (2009) avaliaram o desempenho de bovinos em pastejo submetidos a duas frequências de suplementação (três vezes na semana ou diariamente) no período seco, não observaram diferenças para ganho médio diário, $\mathrm{e}$ concluíram que o desempenho animal não é influenciado pela redução da frequência de suplementação de bovinos, e que a suplementação três vezes na semana deve ser vista como uma forma de diminuir custos operacionais. Em outro experimento conduzido no município de Santo Antônio de Leverger, Mato Grosso, Paula et al. (2010) avaliaram os efeitos do fornecimento diariamente e infrequente (três vezes na semana) de suplementos sobre o ganho de peso de bovinos em pastejo durante o período seco, observaram que os animais que receberam suplementação infrequente obtiveram melhor ganho de peso, também não houve efeito das frequências de suplementação sobre a digestibilidade da matéria seca e consumo fibra em detergente neutro. Outros estudos como os de Canesin et al. (20007), Paula et al. (2011) relatam em suas pesquisas que a suplementação infrequente é vantajosa quando comparada a suplementação diariamente.

Com base na literatura é possível afirmar que a redução na frequência de suplementação não prejudica o desempenho do animal, devido a diversas adaptações fisiológicas, e que essa infrequência na suplementação deve ser vista como uma estratégia para diminuir custos com mão de obra e suplementos no período seco.

\section{Suplementos proteicos alternativos}

A suplementação geralmente é realizada com o objetivo de manter um adequado ganho de peso dos animais no período seco do ano. Segundo Carvalho et al. (2011), neste período, o nutriente considerado como o mais limitante ao desempenho dos animais em pastejo em gramíneas tropicais é a proteína. Ainda de acordo com esses autores, a suplementação proteica torna-se fundamental para diminuir as perdas ou elevar o ganho de peso.

O farelo de soja é o concentrado proteico mais utilizado nos sistemas de produção animal, porém seu alto custo restringe o seu uso em regiões distantes daquelas produtoras de grãos, o que justifica a busca constante por alimentos que venha substituir em partes o farelo de soja. A região Nordeste do Brasil apresenta uma vasta diversidade de leguminosas forrageiras adaptadas ao Semiárido que podem ser utilizadas como fontes proteicas na dieta de ruminantes.

Essas leguminosas adaptadas a região semiárida apresentam em sua composição química, níveis satisfatórios de proteína bruta (Tabela 1) podendo substituir em partes o farelo de soja na composição de dietas para ruminantes em pastejo.

Tabela 1. Teores de proteína bruta (PB), e digestibilidade in vitro da MS (DIVMS) de leguminosas forrageiras

\begin{tabular}{lccl}
\hline Leguminosas & PB (\%) & DIVMS & Fonte \\
\hline Leucena & 16,8 & 48 & Possenti et al. (2008) \\
Leucena & 20 & 45 & Gama et al. (2009) \\
Gliricidia & 24 & - & $\underline{\text { Costa et al. (2009) }}$ \\
\hline
\end{tabular}

A suplementação proteica é vantajosa quando há disponibilidade de forragem, portanto, é importante identificar cultivares adaptadas a longos períodos de falta de água, aliado a isso, o uso de suplementos disponíveis na área, como é o caso, das leguminosas deve ser considerado para reduzir os custos dos sistemas de suplementação. No Nordeste brasileiro, onde grande parte da região está sob curtos periodos de chuvas e altas temperaturas, espécies arbóreas como Leucaena (Leucaena leucocephala) e Gliricidia (Gliricidia sepium) são tolerantes a tais condições e, portanto, têm potencial uso como alimento para ruminantes a baixo custo. Possenti et al. (2008) observaram 
melhor padrão de fermentação, com aumento na produção de ácido propiônico e redução na emissão de metano, quando aumentaram de 20 para $50 \%$ a participação de leucena associada ao feno de coastcross na dieta dos animais.

Outro alimento proteico que pode ser utilizado para a suplementação de animais em pasto em substituição ao farelo de soja, é a torta de algodão, obtida da extração do óleo das sementes do algodão. Normalmente a indústria produz dois tipos de torta de algodão que diferem no teor de PB, que normalmente apresenta de $28 \%$ e $38 \%$ de PB. A proteína degradável no rúmen da torta de algodão corresponde a $63,5 \%$ da $\mathrm{PB}$, enquanto que a do farelo de soja é de aproximadamente $65 \%$ (Guimarães, 2015).

Paula et al. (2011) testaram farelo de soja e torta de algodão na suplementação de bovinos em pastejo no período seco, relatou que a torta de algodão, proporcionou resultados semelhantes ao farelo de soja, e devido ao custo pelo $\mathrm{kg}$ da torta de algodão $(\mathrm{R} \$ 0,35)$ ser inferior ao farelo de soja $(\mathrm{R} \$ 0,49)$, permitiu inferir redução no custo do suplemento, constituindo-se numa fonte proteica alternativa na composição de suplementos múltiplos.

A ureia é um composto rico em nitrogênio que pode ser utilizado para animais em pastejo devido a simbiose com as bactérias ruminais (Arcuri et al., 2011) que utilizam esses compostos para formação de proteína microbiana. Isto é muito vantajoso, pois a ureia possui $45 \%$ de nitrogênio. Cada grama de ureia possui a mesma quantidade de $\mathrm{N}$ que $2,81 \mathrm{~g}$ de proteína verdadeira. A ureia é altamente degradável no rúmen e exige alguns cuidados na sua administração para ruminantes. A sua quebra gera produção de amônia, composto volátil utilizado pelos microrganismos para síntese de proteína microbiana (Guimarães, 2015).

A ureia é um dos ingredientes mais utilizado na formulação de suplementos para ruminantes em pasto, no entanto quando utilizada em pastagens de baixa qualidade, tem-se observado o decréscimo no desempenho quando se ultrapassa $3 \%$ de ureia no suplemento (Moraes et al., 2010). A ureia talvez constitua o principal e mais potente limitador de consumo utilizado na composição de suplementos múltiplos de autoconsumo (Fernandes et al., 2013), dai a explicação para decréscimo no desempenho quando aumenta o nível de ureia. Todos esses alimentos têm potencial de substituir o farelo de soja, de forma parcial, diminuindo os custos de produção.

\section{Conclusão}

A suplementação alimentar para animais em pasto, é uma estratégia que deve ser adotada pelos pecuaristas, principalmente nos períodos de escassez de alimento, pois mesmo com menor disponibilidade qualitativa e quantitativa da forragem, permite maiores ganhos individuais e por área e possibilita aumento na capacidade de suporte das pastagens. O que resulta em um menor tempo de terminação, com um retorno mais rápido do capital investido.

Outro fato relevante em relação a suplementação é que é possível afirmar que a redução na frequência de suplementação não prejudica o desempenho do animal, e que essa infrequência na suplementação deve ser vista como uma estratégia para diminuir custos com mão de obra e suplementos no período seco.

$\mathrm{O}$ uso de alimentos alternativos proteicos deve ser estimulado, pois diminui a dependência de produtos tradicionais oriundos de outras regiões do país.

\section{Referências Bibliográficas}

Amorim, D. S., Silva, A. L., Sousa, S. V., Sousa, P. H. A. A. \& Reis, Á. L. A. 2017. Caracterização e restrições de forrageiras indicadas para as diferentes espécies de animais de produção-revisão. Revista Eletrônica Científica da UERGS, 3, 215-237.

ANUALPEC. 2017. Anuário da Pecuária Brasileira, 20th edn. Instituto FNP, São Paulo, SP, Brasil.

Arcuri, P. B., Lopes, F. C. F. \& Carneiro, J. C. 2011. Microbiologia do rumen. In: Berchielli, T. T., Pires, A. V. \& Oliveira, S. G. (eds.) Nutrição de Ruminantes. FUNEP, Jaboticabal, Brazil.

Bargo, F., Muller, L. D., Kolver, E. S. \& Delahoy, J. E. 2003. Invited review: Production and digestion of supplemented dairy cows on pasture. Journal of Dairy Science, 86, 1-42.

Berchielli, T. T., Pires, A. V. \& Oliveira, S. G. 2011. Nutrição de Ruminantes. FUNEP, Jaboticabal, Brazil.

Bohnert, D., Schauer, C., Bauer, M. \& DelCurto, T. 2002. Influence of rumen protein degradability and supplementation frequency on steers consuming low-quality forage: I. Site 
of digestion and microbial efficiency. Journal of Animal Science, 80, 2967-2977.

Canesin, R.C. Berchielli, T. T., Andrade, P.De \& Reis, R. A. 2007. Desempenho de bovinos de corte mantidos em pastagem de capim marandu submetidos a diferentes estratégias de suplementação no período das águas e da seca. Revista Brasileira de Zootecnia, 36, 411-420.

Canesin, R. C., Berchielli, T. T., Reis, R. A., Baldi, F. S. R., Resende, K. T. \& Teixeira, I. A. M. A. 2009. Desempenho de bovinos em pastejo submetidos a duas frequências de suplementação no período da seca. Acta Scientiarum. Animal Sciences, 31, 411-420.

Cardoso, A. R., Carvalho, S., Galvani, D. B., Pires, C. C. \& Gasperin, B. G. 2006. Comportamento ingestivo de cordeiros alimentados com dietas contendo diferentes níveis de fibra em detergente neutro. Ciência Rural, 36, 604-609.

Carvalho, D. M. G., Silva Cabral, L., Zervoudakis, J. T., Arnoldo, T. L. Q., Benatti, J. M. B., Koscheck, J. F. W., Piona, M. N. M. \& Oliveira, A. A. 2011. Suplementos para ovinos mantidos em pastos de capim-marandu. Pesquisa Agropecuária Brasileira, 46, 196204.

Costa, B. M., Santos, I. C. V., Oliveira, G. J. C. \& Pereira, I. G. 2009. Avaliação de folhas de gliricidia sepium (JACQ.) walp por ovinos. Archivos de Zootecnia, 58, 33-41.

Dixon, R. M. \& Stockdale, C. R. 1999. Associative effects between forages and grains: consequences for feed utilisation. Australian Journal of Agricultural Research, 50, 757-774.

Emerenciano Neto, J. V., Santos, D. G., Aguiar, E. M., Fernandes, L. S., Oliveira, H. C. B. \& Trindade, S. M. G. 2014. Performance of meat sheep, chemical composition and structure of tropical pasture grasses managed under intermittent capacity. Bioscience Journal, 30, 834-842.

Emerenciano Neto, J. V., Santos, D. G., Lana, A. M. Q., Campos, N. R. F., Lima, V. E. L. \& Moraes, J. D. 2017. Sward structure and herbage accumulation of massai guineagrass pastures managed according to pre-grazing heights, in the northeast of Brazil. Journal of Agricultural Science, 9, 155-193.

Euclides, V. P. B., Euclides Filho, K., De Arruda, Z. J. \& Figueiredo, G. R. 1998. Desempenho de novilhos em pastagens de Brachiaria decumbens submetidos a diferentes regimes alimentares. Revista Brasileira de Zootecnia, 27, 246-254.

Farinatti, L. H. E., Rocha, M. G., Poli, C. H. E. C., Pires, C. C., Potter, L. \& Silva, J. H. S. 2006. Desempenho de ovinos recebendo suplementos ou mantidos exclusivamente em pastagem de azevém (Lolium multiflorum Lam.). Revista brasileira de zootecnia, 35, 527-534.

Fernandes, G. A., Fernandes, F. F. D., Mousquer, C. J., Freiria, L. B., Feijó, L. C., Castro, W. J. R., Silva, M. R. \& Silva Filho, A. S. 2013. Suplementação de bovinos de corte em pastejo. PUBVET, 7, 2189-2326.

Fernandes, L. S., Difante, G. d. S., Montagner, D. B., Emerenciano Neto, J. V., Araújo, I. M. M. \& Campos, N. R. F. 2017. Structure of massai grass pasture grazed on by sheep supplemented in the dry season. Grassland Science, 63, 177183.

Gama, T. C. M., Zago, V. C. P., Nicodemo, M. L. F., Laura, V. A., Volpe, E. \& Morais, M. G. 2009. Composição bromatológica, digestibilidade "in vitro" e produção de biomassa de leguminosas forrageiras lenhosas cultivadas em solo arenoso. Revista Brasileira de Saúde e Produção Animal, 10, 560-572.

Geron, L. J. V., Mexia, A. A., Garcia, J., Silva, M. M. \& Zeoula, L. M. 2012. Suplementação concentrada para cordeiros terminados a pasto sobre custo de produção no período da seca. Semina: Ciências Agrárias, 33, 797-808.

Goes, R. H. T. B., Mancio, A. B., Alves, D. D. \& Lana, R. L. 2005. Freqüência de suplementação da dieta de novilhos em recria, mantidos no pasto de Brachiaria brizantha na região amazônica. Desempenho animal. Acta Scientiarum. Animal Sciences, 27, 491-496.

Guimarães, T. P. 2015. Exigências proteicas para bovinos de corte. Multi-Science Journal, 1, 9099.

Gurgel, A. L. C., Difante, G. S., Emerenciano Neto, J. V., Souza, J. S., Veras, E. L. L., Costa, A. B. G., Netto, R. T. C., Fernandes, L. S., Cunha, J. C. \& Roberto, F. F. S. 2017. Estrutura do pasto e desempenho de ovinos em capim-massai na época seca em resposta ao manejo do período das águas. Boletim de Indústria Animal, 74, 86-95.

Hodgson, J. 1990. Grazing management. Science into practice. Longman Group UK Ltd., London. 
Leng, R. A. 1990. Factors affecting the utilization of 'poor-quality'forages by ruminants particularly under tropical conditions. Nutrition Research Reviews, 3, 277-303.

Minson, D. 2012. Forage in ruminant nutrition. Academic Press, New York.

Moore, J. E., Brant, M. H., Kunkle, W. E. \& Hopkins, D. I. 1999. Effects of supplementation on voluntary forage intake, diet digestibility, and animal performance. Journal of Animal Science, 77, 122-135.

Moraes, E. H. B. K., Paulino, M. F., Valadares Filho, S. C., Moraes, K. A. K., Detmann, E. \& Gonçalves, M. 2010. Avaliação nutricional de estratégias de suplementação para bovinos de corte durante a estação da seca. Revista Brasileira de Zootecnia, 39, 608-616.

Morais, J. A. S., Berchielli, T. T., Queiroz, M. F. S., Keli, A., Reis, R. A. \& Souza, S. F. 2009. Influência da frequência de suplementação no consumo, na digestibilidade e na fermentação ruminal em novilhos de corte mantidos em pastagem de capim-marandu. Revista Brasileira de Zootecnia, 38, 1824-1834.

Moreira, F. B., Prado, I. N., Cecato, U., Wada, F. Y. \& Mizubuti, I. Y. 2004a. Forage evaluation, chemical composition, and in vitro digestibility of continuously grazed star grass. Animal Feed Science and Technology, 113, 239-249.

Moreira, F. B., Prado, I. N., Cecato, U., Wada, F. Y., Nascimento, W. G. \& Souza, N. E. 2003. Suplementação com sal mineral proteinado para bovinos de corte, em crescimento e terminação, mantidos em pastagem de grama estrela roxa (Cynodon plectostachyrus Pilger) no inverno. Revista Brasileira de Zootecnia, 32, 449-455.

Moreira, F. B., Prado, I. N., Cecato, U., Zeoula, L. M., Wada, F. Y. \& Torii, M. S. 2004b. Níveis de suplementação com sal mineral proteinado para novilhos Nelore terminados em pastagem no período de baixa produção forrageira. Revista Brasileira de Zootecnia, 33, 18141821.

Moreira, F. B., Prado, I. N., Souza, N. E., Matsushita, M., Mizubitu, I. Y. \& Macedo, L. M. A. 2005. Desempenho animal e características da carcaça de novilhos terminados em pastagem de aveia preta, com ou sem suplementação energética. Acta Scienciarum. Animal Sciences, 27, 469-473.
NRC. 2000. Nutrient Requirements of Beef Cattle, 7th rev. edn. Natl. Acad. Press, Washington, DC, USA.

Paula, N. F., Zervoudakis, J. T., Cabral, L. S., Carvalho, D. M. G., Hatamoto-Zervoudakis, L. K., Moraes, E. H. B. K. \& Oliveira, A. A. 2010. Frequência de suplementação e fontes de proteína para recria de bovinos em pastejo no período seco: desempenho produtivo e econômico. Revista Brasileira de Zootecnia, 9, 837-882.

Paula, N. F., Zervoudakis, J. T., Silva Cabral, L., Carvalho, D. M. G., Paulino, M. F., HatamotoZervoudakis, L. K., Oliveira, A. A. \& Koscheck, J. F. W. 2011. Suplementação infrequente e fontes proteicas para recria de bovinos em pastejo no período seco: parâmetros nutricionais1. Revista Brasileira de Zootecnia, 40, 882-891.

Possenti, R. A., Franzolin, R., Schammas, E. A., Demarchi, J., Frighetto, R. T. S. \& Lima, M. 2008. Efeitos de dietas contendo Leucaena leucocephala e Saccharomyces cerevisiae sobre a fermentação ruminal ea emissão de gás metano em bovinos. Revista Brasileira de Zootecnia, 37, 1509-1516.

Prado, I. N. 2010. Produção de bovinos de corte e qualidade da carne. Eduem, Maringá, Paraná, Brasil.

Prado, I. N., Moreira, F. B., Prado, R. M. \& Rotta, P. P. 2010. Alimentos usados para supelementação de bovinos de corte. In: Prado, I. N. (ed.) Produção de bovinos de corte e qualidade da carne. Eduem, Maringá, Paraná, Brasil.

Reis, R. A., Ruggieri, A. C., Casagrande, D. R. \& Páscoa, A. G. 2009. Suplementação da dieta de bovinos de corte como estratégia do manejo das pastagens. Revista Brasileira de Zootecnia, $38,147-159$.

Restle, J., Roso, C., Oliveira, A. N., Alves Filho, D. C., Pascoal, L. L. \& Pereira Rosa, J. R. 2000. Suplementaçáo energética para vacas de descarte de diferentes idades em terminação em pastagem cultivada de estação fria sob pastejo. Revista Brasileira de Zootecnia, 29, 1216-1222.

Silva, R. R., Prado, I. N., Carvalho, G. G. P., Silva, F. F., Almeida, V. V. S., Santana Júnior, H. A., Paixão, M. L. \& Abreu Filho, G. 2010. Níveis de suplementação na terminação de novilhos Nelore em pastagens: aspectos econômicos. 
Revista Brasileira de Zootecnia, 39, 20912097.

Simioni, F. L., Andrade, I. F., Ladeira, M. M., Gonçalves, T. M., Mata Júnior, J. I. \& Rodrigues, C. F. 2009. Níveis e frequência de suplementação de novilhos de corte a pasto na estação seca. Revista Brasileira de Zootecnia, 38, 2045-2052.

Tonello, C. L., Branco, A. F., Yuji, T. C., Ribeiro, B. L., Castañeda, S. R. \& Coneglian, M. S. 2011. Suplementação sobre o desempenho de bovinos de corte em pastagens: época do ano. Semina: Ciências Agrárias, 32, 373-382.
Valadares Filho, S. C., Costa e Silva, L. F., Gionbelli, M. P., Rotta, P. P., Marcondes, M. I., Chizzotti, M. L. \& Prados, L. F. 2016. Exigências nutricionais de zebuínos puros e cruzado - BR-Corte. Universidade Federal de Viçosa, Viçosa, Minas Gerais.

Article History:

Received 24 December 2017

Accepted 16 February 2018

Available online 21 March 2018

License information: This is an open-access article distributed under the terms of the Creative Commons Attribution License 4.0, which permits unrestricted use, distribution, and reproduction in any medium, provided the original work is properly cited. 